\title{
Docência e Educação de Jovens e Adultos: Um Olhar sob as Lentes de Pesquisadores da UERGS
}

\author{
Youth and Adult Education (YAE) and Teaching: A Look under the Lenses \\ of UERGS Researchers.
}

\section{Educación y enseñanza para jóvenes y adultos (EJA): una mirada bajo las lentes de los investigadores de UERGS.}

\author{
Sita Mara Lopes Sant'Anna ${ }^{1}$ \\ Catiana Dias Gafforelli ${ }^{2}$ \\ Odilon Antônio Stramare ${ }^{3}$ \\ Camila dos Santos Padilha ${ }^{4}$
}

\begin{abstract}
Resumo
Este artigo objetiva apresentar excertos de levantamentos, estudos e pesquisas desenvolvidas através do Grupo de Pesquisa do CNPq, intitulado: Educação de Jovens e Adultos: docência, formação de professores e processos pedagógicos da EJA, que visa mapear a constituição da docência em EJA no Rio Grande do Sul - Brasil. Para tanto, o artigo apresenta um estudo teórico sobre a docência na EJA; levantamento sobre a docência em produções stricto-sensu nas Instituições de Ensino Superior (IES) públicas do Estado; resultado parcial de pesquisa sobre abordagens de EJA no projetos de cursos de licenciaturas da Universidade Estadual do Rio Grande do Sul e a constituição da oferta de EJA/Educação Básica, núcleos e grupos de pesquisa, em 2018. O que nos mobiliza a produção desse levantamento é o questionamento de como a docência na EJA vem sendo abrangida, conceitualmente, nas pesquisas de mestrado, na formação inicial e em abordagens de oferta na Educação Básica. Do ponto de vista metodológico, parte-se de orientações da pesquisa qualitativa em educação para a execução dos levantamentos. Como resultados, pode-se afirmar que a docência se mostra multirreferenciada, por diferentes nuances e a EJA passa a ser compreendida como campo árido de estudos. Importante salientar, também, que estes estudos apresentados em Jaguarão, já surtem efeitos, tanto no que tange à ampliação de núcleos e grupos de pesquisa nas IES públicas, quanto no que se refere a movimentos de revisão dos currículos das licenciaturas. Este, talvez, seja o mais significativo entre os efeitos observados.
\end{abstract}

Palavras-chave: Educação de Jovens e Adultos; docência; pesquisas e levantamentos sobre EJA; modalidade EJA; currículo licenciaturas.

\footnotetext{
${ }^{1}$ Doutora em Educação. Professora Adjunta da Universidade Estadual do Rio Grande do Sul e permanente do Programa de Pós-Graduação em Educação - Mestrado Profissional/PPGED-MP/UERGS/CAPES. Lattes.cnpq.br/5195153340421188.E-mail: sitamarals@yahoo.com.br

2 Mestra em Educação na Universidade Estadual do Rio Grande do Sul, Unidade Litoral Norte-Osório. Professora da Educação Básica na Rede Municipal de Osório e Estadual. Lattes.cnpq.br/1077601052752603. Email: catianagafforelli@gmail.com

${ }^{3}$ Mestre em Geociências, Licenciado em Pedagogia. Especialista em Programa Nacional de Integração da Educação Profissional com a Educação Básica na Modalidade de Educação de Jovens e Adultos Proeja. Professor da Universidade Estadual do Rio Grande do Sul. Lattes.cnpq.br/1097265601119497 E-mail: straodin@yahoo.com.br

4 Licencianda em Letras da Universidade Estadual do Rio Grande do Sul. Bolsista do projeto de pesquisa intitulado: Docência e formação inicial: vozes de licenciandas e licenciandos sobre as práticas de estágio em EJA, pela PROPPG/UERGS. Lattes.cnpq.br/1617957741971940 E-mail: camilasspadilha@gmail.com
} 


\begin{abstract}
This article aims to present excerpts from surveys, studies and research on the use of the National Research Council of Brazil - CNPq Research Group, entitled: Youth and Adult Education: teaching, teacher training and YAE pedagogical processes, which seen map the constitution of teaching in YAE in Rio Grande do Sul, Brazil. To this end, the article presents a theoretical study on teaching at EJA; survey on teaching in strict-sensory productions in public Higher Education Institutions (HEIs) in the State; partial result of research on EJA approaches in the design of undergraduate courses at the State University of Rio Grande do Sul education offering and constitution of YAE / Basic Education, nuclei and research groups, in 2018. What mobilizes us to produce this value is or questioning how teaching at EJA has been comprehensive, conceptual, in master's research, in initial training and in approaches to offering in Basic Education. Make a methodological point of view, be part of qualitative research guidelines in education for carrying out surveys. As a result, it can be indicated that teaching is multi-referenced, due to different nuances and EJA is now understood as an arid field of study. It is also important to note that these studies presented at Jaguarão city, are already having an effect, both with regard to the expansion of nuclei and research groups in public HEIs, as well as not referring to the revision of license curricula. This, perhaps, is the most significant among the observed effects.
\end{abstract}

Keywords: Youth and Adult Education; Teaching; YAE research and surveys; YAE mode; education degree curriculum.

\title{
Resumen
}

Este artículo tiene como objetivo presentar extractos de encuestas, estudios e investigaciones desarrollados a través del Grupo de Investigación CNPq- de Brasil, titulado: Educación de jóvenes y adultos: enseñanza, capacitación docente y procesos pedagógicos de EJA, cuyo objetivo es mapear la constitución de la enseñanza en EJA en Río Grande do Sul. Con este fin, el artículo presenta un estudio teórico sobre la enseñanza en EJA; encuesta sobre la enseñanza en producciones estrictamente en las instituciones de educación superior (IES) del estado; resultado parcial de la investigación sobre los enfoques de EJA en proyectos de cursos de pregrado en la Universidad Estatal de Rio Grande do Sul y la constitución de la oferta de EJA/Educación Básica, centros y grupos de investigación, en 2018. Lo que nos moviliza para producir esta encuesta Es el cuestionamiento de cómo la enseñanza en EJA se ha cubierto conceptualmente en la investigación de maestría, en la capacitación inicial y en la oferta de enfoques en educación básica. Desde un punto de vista metodológico, se basa en pautas de investigación cualitativa en educación para realizar encuestas. Como resultado, se puede decir que la enseñanza tiene múltiples referencias, debido a diferentes matices y que EJA ahora se entiende como un campo de estudio árido. Es importante tener en cuenta que estos estudios presentados en Jaguarão, ya tienen efectos, tanto con respecto a la expansión de núcleos y grupos de investigación en IES públicas, como con respecto a la revisión de los planes de estudios de los títulos de pregrado. Este, quizás, es el más significativo entre los efectos observados.

Palabras clave: Educación de Jóvenes y Adultos; enseñanza; EJA investigación y encuestas; modo EJA; plan de estudios de licenciatura.

\section{Introdução}

O presente texto que apresentamos é resultado de um estudo contendo referenciais, levantamentos e reflexões que vimos produzindo sobre docência e formação docente na Educação de Jovens e Adultos - EJA ${ }^{5}$. Desse modo, o artigo organiza-se a partir de quatro subtítulos em referência “ ao olhar sobre as lentes", a saber: estudo teórico para reflexão sobre a docência na EJA; a docência em produções stricto-sensu nas Instituições de Ensino Superior

\footnotetext{
${ }^{5}$ Vinculados ao Grupo de Pesquisa do CNPq: Educação de Jovens e Adultos: docência, formação de professores e processos pedagógicos da EJA.
} 
(IES) públicas do Rio Grande do Sul; abordagens de EJA no projetos de cursos de licenciaturas da Universidade Estadual do Rio Grande do Sul e a oferta de EJA/Educação Básica e em núcleos e grupos de pesquisa.

Nesta perspectiva, do ponto de vista metodológico, parte-se dos pressupostos da pesquisa qualitativa em educação, em relação aos estudos que serão apresentados.

O conceito de docência é complexo, está em constante movimento e apresenta-se sob diferentes perspectivas. Segundo Laffin (2013, p.81) a docência compreende "múltiplas dimensões e concepções presentes no fazer docente". Além disso, percebe-se que na EJA, a docência apresenta-se com as especificidades que constituem esta modalidade.

\section{A Docência e a EJA}

Entre as pesquisas que tratam sobre a docência, há as que apontam para a necessidade de se formalizar e nomear os conhecimentos do magistério. Tal formalização passa primeiro pelas características próprias à atividade do professor em sala de aula e, em seguida, pela comprovação dos saberes por ele mobilizados. Assim, ao abranger a docência ${ }^{6}$ compreende-se que a mesma pode ser abordada a partir de suas múltiplas dimensões e que podem envolver o ser docente, o trabalho docente, a sua formação inicial e continuada, os seus saberes, competências, habilidades, processos identitários diversos, e quando somada à EJA, incorpora as especificidades deste campo de saberes.

Dentre o conjunto de trabalhos que vimos efetivando, localiza-se o estudo de Tardif (2002), que relaciona os "saberes" aos processos identitários da profissão, vida e formação docente. Nessa perspectiva, o professor dispõe de um sistema cognitivo, mas não se reduz a ele, pois possui uma história de vida, é um ator social, tem emoções, um corpo, poderes, personalidade, culturas e seus pensamentos e ações carregam as representações dos contextos vividos.

O autor define o saber docente como plural, pois o considera como formado pela fusão de "saberes pessoais dos professores" oriundos da formação escolar anterior, da sua experiência escolar, da sua formação profissional e de "sua própria experiência na profissão, na sala de aula e na escola: adquiridos na prática, na sala de aula, com seus pares, etc.”. (TARDIF, 2002, p. 63). O que se observa nesta categorização, proposta por Tardif, é que os professores têm saberes e que estes são utilizados no contexto de sua profissão e de sala de

\footnotetext{
${ }^{6}$ A docência, no âmbito do trabalho docente, pode compreender a prática de ensino, a postura investigativa, o diálogo com a comunidade e a gestão educacional.
} 
aula. Nesse sentido, o saber profissional do professor está na convergência das várias vertentes de saberes "provenientes da história de vida individual, da sociedade, da instituição escolar, dos outros atores educativos, dos lugares de formação, etc.” (TARDIF, 2002, p.64).

Contribuindo para reflexão sobre a concepção de saberes docentes, busca-se em Nóvoa (1999), as abordagens sobre a formação de professores, deslocando-as de uma perspectiva excessivamente centrada nas dimensões acadêmicas (áreas, currículos, disciplinas, etc.) para uma perspectiva centrada no terreno profissional, que reproduz na memória o percurso histórico de formação da profissão docente. Nessa perspectiva, o autor aponta a necessidade de pensar a formação de professores, a partir de uma reflexão fundamental sobre a profissão docente. $\mathrm{O}$ autor relaciona a formação de professores com o desenvolvimento pessoal (produzir a vida do professor), com o desenvolvimento profissional (produzir a profissão docente) e com o desenvolvimento organizacional (produzir a escola). (NÓVOA, 1999, p. 12).

Assim, propõe um modelo baseado na inter-relação de três tipos de saberes que se vinculam de diferentes maneiras na produção da profissão docente: o saber da experiência (produzido pelos professores), o saber da pedagogia (produzido pelos especialistas em ciências da educação) e os saberes das disciplinas (produzidos por especialistas dos diferentes domínios do conhecimento). Esses três tipos de saberes estão relacionados como vértices de um triângulo. No entanto, segundo Nóvoa, atualmente ocorrem ligações privilegiadas entre os dois vértices que representam os saberes de tipo científico (da pedagogia e das outras disciplinas).

Em publicação intitulada "A análise de charges sobre professores", das autoras Fiss e Spies (2015), as mesmas tratam do mal-estar docente e das representações da mídia, sobre os efeitos de sentidos de crise no Magistério. Nesse sentido, falam da falta de reconhecimento dos saberes dos professores e dizem que isso ocorre "porque os conhecimentos que constituem a ação e investigação" dos docentes "não são legitimados pelas demais ciências" (FISS, SPIES, 2015, p. 100). Para além dos fatores políticos que envolvem o desprestígio profissional, nesse estudo, a docência é compreendida por uma imagem veiculada nas charges enquanto campo profissional de entrega, messianismo e vocação. Deste modo, as mídias e redes sociais influenciam nos modos como a docência é representada, socialmente, atuando, inclusive, no imaginário dos próprios professores, reforçando imagens de desprestígio profissional. 
Valendo-se da metáfora do jogo de bridge ${ }^{7}$, Nóvoa (1999, p.10), tomando por base as políticas para a docência, afirma que os professores têm assumido o lugar do morto nos discursos educacionais, pois [...] nenhuma jogada pode ser delineada sem ter em atenção às cartas que estão em cima da mesa, mas o jogador que as possui, não pode ter uma estratégia própria: ele é o referencial passivo de todos os outros. Nóvoa (1999), apresenta o triângulo político, formado pelo Estado, pelos pais/comunidades e pelos professores. Por meio de tal esquema, o autor analisa os modos de organização do sistema educativo.

Esse modelo de análise auxilia-nos a perceber algumas das contradições presentes no movimento atual de profissionalização do magistério. A intensa atividade dos especialistas em educação e nas disciplinas de ensino, que resulta em uma crescente sofisticação dos discursos pedagógicos, delineia novos horizontes profissionais para a docência. Tais discursos, como dito, enfatizam, inclusive, o valor das experiências e dos saberes docentes. Porém, paradoxalmente, essa valorização social docente reverte-se em maior controle sobre os professores, já que eles próprios não estão envolvidos na produção de seu novo lugar profissional. Soma-se a isso, uma frágil imagem da profissão, veiculada socialmente. Nessa perspectiva, os professores, assumindo o lugar do morto no jogo descrito por Nóvoa, atuam como consumidores de discursos acadêmicos e de produtos formativos, tendo em vista atender às elevadas expectativas que são geradas a respeito de sua identidade, como expert, profissional reflexivo, autônomo e eficaz.

Embora situem-se diferenças entre os saberes docentes e suas trajetórias e as competências, como saber fazer profissional, buscou-se, também, em Perrenoud (2000), elementos que situam a especialização dos professores contemporâneos entre a decisão na incerteza e a ação na urgência ${ }^{8}$. Propõe, o autor, um inventário das competências necessárias para o desenvolvimento do trabalho docente definidas em 10 grandes famílias, a saber: organizar e dirigir situações de aprendizagem; administrar a progressão das aprendizagens; conceber e fazer evoluir os dispositivos de diferenciação; envolver os alunos em suas aprendizagens e em seu trabalho; trabalhar em equipe; participar da administração da escola; informar e envolver os pais; utilizar novas tecnologias; enfrentar os deveres e os dilemas éticos da profissão; administrar sua própria formação contínua. (PERRENOUD, 2000, p. 14).

\footnotetext{
${ }^{7}$ Essa metáfora já fora anteriormente empregada por Jean Houssaye (1988) na apresentação de seu triângulo pedagógico. No triângulo pedagógico, Houssaye propõe a consideração dos modelos pedagógicos a partir da interação entre três elementos: o sujeito que ensina, o aluno e conteúdo do ensino

${ }^{8}$ Para Perrenoud, agir na urgência não é o mesmo que agir com urgência. A ideia de urgência está relacionada a valorizar o instante afim de mobilizar os melhores recursos em favor dos alunos. Nesse sentido, decidir na incerteza é tomar decisões num contexto em que os resultados não são previsíveis.
} 
$\mathrm{O}$ autor entende competência como "capacidade de mobilizar diversos recursos cognitivos para enfrentar um tipo de situações”. (Idem, p. 15). O pensamento situado, intuitivamente, prevê que os professores desenvolvem "esquemas de pensamento próprios".

Tratando da primeira competência, "organizar e dirigir situações de aprendizagem”, propõe que na aula magistral o professor não domina as situações de aprendizado, pois as múltiplas vivências dos alunos estão fora do contexto abordado. Ao organizar e dirigir situações de aprendizagem, o professor dispende energias para criar novas e eficazes situações de aprendizagem, encaradas contemporaneamente como amplas, abertas, carregadas de sentido e regulação (PERRENOUD, 2000, p.26), mobilizando portanto outras competências específicas, a saber: Conhecer [...]os conteúdos a serem ensinados e sua tradução em objetivos de aprendizagem; trabalhar a partir das representações dos alunos; trabalhar a partir dos erros e dos obstáculos à aprendizagem; construir e planejar dispositivos e sequências didáticas; envolver os alunos em atividades de pesquisa, em projetos de conhecimento.

Para o autor, dominar o conteúdo não é o suficiente para bem ensiná-lo, é preciso também que o docente seja capaz de reconstruí-lo em situações complexas. Para tanto, os professores precisam transitar entre os conteúdos, os objetivos e as situações, por meio da transposição didática. Ele lembra dos obstáculos pedagógicos e de como os professores tendem a esquecer-se de como aprenderam e que os alunos não têm dificuldades porque querem. Seria também útil para esta competência que os professores analisassem a história da ciência e percebessem que esta também se encontra em dificuldades com conceitos elementares. Para Perrenoud, aprender é "reestruturar seu sistema de compreensão de mundo". (PERRENOUD, 2000, p. 30). Nesse caso, os alunos apropriam-se do problema, criam e superam obstáculos, constroem hipóteses e experiências. No coletivo isso leva ao choque de representações, precisando o pensamento e reconhecendo o alheio.

Para desenvolver a capacidade de envolver os alunos em atividades de pesquisa, em projetos de conhecimento, Perrenoud (2000), propõe que os alunos precisam aceitar a tarefa. Para tanto, é preciso que os alunos se envolvam numa atividade de uma certa importância e de uma certa duração. A tarefa de deixar o conhecimento apaixonante não é apenas uma competência, mas participa da identidade e do projeto pessoal do professor.

No que tange à docência na EJA, o trabalho de Laffin (2013) revela que são múltiplas as concepções sobre a docência e que os trabalhos assumem características e definições com cada campo teórico. Em seus estudos, abrange uma compreensão de docência de modo geral, mas considera a docência como multifacetada e influenciada pela legislação, concepções de 
ensino e aprendizagem, pelas condições do trabalho do professor, no próprio exercício de docência desenvolvido e por meio de um processo de reflexão na e sobre a ação pedagógica.

Nessa perspectiva, a docência, "sempre em estado de inacabamento" envolve o aspecto legal, o teórico e a prática docente. Porém, bem como afirma, também, Sant' Anna (2015), é permeada por uma história que remete os professores a poucas políticas públicas de estado e muitas políticas públicas de governo, que não são perenes e que seguem outras políticas, envolvendo a constituição e adequação de currículos, avaliação nacional, que é seletiva e classificatória e a constituição das políticas da sua formação, enquanto profissionais.

Para Laffin (2013, p. 35) é preciso considerar, ainda, que a educação é vista por um ponto de vista de interesses, envolvendo organizações internacionais que pensam a educação na lógica de mercado, como o Banco mundial e Fundo Monetário Internacional, que influenciam as políticas educacionais no Brasil. Além da avaliação nacional e da descentralização da gestão, que tem sido foco destes organismos, a educação ainda absorve modelos de gestão empresarial de controle e de processos.

Dos estudos de Laffin (2013) sobre docência, produz-se o seguinte quadro sinóptico ${ }^{9}$ visando uma melhor compreensão dos aspectos apontados pela autora:

Quadro 1 - O que a docência reflete e o tornar-se professor

\begin{tabular}{|c|c|}
\hline $\begin{array}{l}\text { A constituição da } \\
\text { docência se dá: }\end{array}$ & $\begin{array}{l}\text { - Pela legislação; } \\
\text { - Pelas concepções de ensino/aprendizagem; } \\
\text { - Pelas condições de trabalho; } \\
\text { - No exercício da docência; } \\
\text { - } \quad \text { Por meio da reflexão na ação. }\end{array}$ \\
\hline A docência reflete: & $\begin{array}{l}\text { - Um processo de apropriação da história individual dos } \\
\text { sujeitos; } \\
\text { - As histórias das práticas educativas; } \\
\text { - As marcas das normas coletivas; } \\
\text { - As particularidades, a complexidade epistemológica e a } \\
\text { - } \text { prática social; } \\
\text { - } \text { Processo de transformação intencional e planejado. }\end{array}$ \\
\hline O tornar-se professor: & $\begin{array}{l}\text { - É condição permanente da docência; } \\
\text { - Se dá na formação inicial e continuada, nas condições } \\
\text { de trabalho; } \\
\text { - É permeado pelos marcos legais, institucionais e sociais. }\end{array}$ \\
\hline
\end{tabular}

Fonte: Gafforelli, Catiana Dias. $(2018)^{10}$

\footnotetext{
${ }^{9}$ É um resumo esquematizado de uma ideia, de um texto. Sua vantagem é que permite a visualização da estrutura e da organização do conteúdo que expõe o texto. (Dicionário Houaiss da Língua Portuguesa, 2011).
} 
É deste contexto que a autora faz abordagem sobre a docência na EJA, mas situando que alguns documentos legais que lhes são próprios, possuem discursos que fazem o contraponto com a ordem vigente. Dentre esses, a autora dá destaque ao parecer n. 11 (BRASIL, 2000).

Conforme Laffin (2013, p. 38) enuncia, para a Lei de Diretrizes e Bases da Educação Nacional (BRASIL, 1996), a docência ganha um caráter multidisciplinar e especializada, ao acentuar a formação inicial de professores na educação superior e a formação continuada como necessidade.

Sobre a docência na EJA, sua atenção se volta, particularmente, para a docência neste campo de conhecimento. Professores que atuam na EJA precisam ter clareza de que pensar e fazer educação deve levar em conta o direito dos sujeitos da Educação de Jovens e Adultos iniciarem e concluírem sua escolarização. Além disso, cabe destacar que a docência na EJA ocupa um lugar de luta e resistência, devido a desvalorização de uma modalidade de ensino ainda por muitos desconhecida. Segundo Laffin (2013), há um apagamento na educação superior da necessidade de se estudar uma educação para sujeitos da EJA.

Desta perspectiva, a autora evoca que à EJA pressupõe "nutrir-se do geral e também, das especificidades que a habilitação requer". Nesse intuito, se propõe a saber como os estudos compreendem a docência. Parte da pesquisa de Haddad (2000) sobre "o estado da arte referente a produção acadêmica discente dos programas de Pós-graduação Stricto-Sensu em Educação de Jovens e Adultos. A respeito, enuncia que no estudo prevalecem pesquisas de tipo qualitativo, com métodos etnográficos. A pesquisa mostra ainda, que sobre a docência aparece uma aproximação entre as realidades experienciadas nas escolas que ofertam EJA. Porém, o autor chama a atenção da necessidade de que os professores lancem um olhar sobre a sua própria atuação, a necessidade de aproximar questões do mundo do trabalho e do emprego na escola.

Os estudos de Sant'Anna (2009) revelam, também, a necessidade de se enfocar a EJA, enquanto campo de saber e de conhecimentos. Analisando as políticas públicas educacionais de formação de professores dessa modalidade, no Rio Grande do Sul, a autora propõe que a docência na EJA se constitua por espaços de formação que se fundamentem nos princípios da

\footnotetext{
${ }^{10}$ In: GAFORELLI, Catiana Dias. Projeto de Pesquisa: Os sentidos da docência nos dizeres dos professores da Educação de Jovens e Adultos em Osório-RS, Universidade Estadual do Rio Grande do Sul, 2018.
} 
história da própria EJA “como essencialmente dialógico, no coletivo das relações, mediante escuta, participação, construção coletiva" com os professores.

Outra contribuição aos estudos, refere-se ao conceito de docência, sob o olhar da “dodiscência” expressa por Freire (1997). Para ele, docência é concebida como postura epistemológica, constituída da relação dialógica em que o aprender e ensinar se processam, "em comunhão". A dodiscência, categoria eminentemente freireana, nos conduz a pensar no inacabamento, nas condições relacionais que se estabelecem em educação e que caracterizam a docência, sempre em constituição como constituída de instâncias de incertezas, diálogo, aprendizagens e formação constante.

A partir dos estudos sobre docência realizados até o memento, pode-se afirmar que a mesma envolve uma multiplicidade constitutiva conceitual, pela interação com as condições da realidade que cerca os professores; com as próprias representações e valores sociais que lhes são atribuídas; pelas condições e exigências de trabalho, incluindo as normativas e legais; as memórias institucionais e porque não dizer, as discursivas, que compõem os discursos externos e os interiorizados.

\section{A Docência na EJA, em Dissertações}

Visando saber como se percebe a docência em pesquisas de mestrado nas IES públicas, realizou-se, também, um levantamento de informações junto ao Sistema de Informatização de Bibliotecas das universidades ${ }^{11}$ : Universidade Federal de Pelotas (UFPel), Universidade Federal de Santa Maria (UFSM), Universidade Federal do Rio Grande do Sul (UFRGS), Universidade Federal da Fronteira Sul e Universidade Federal do Rio Grande (FURG). A fim de localizar os estudos, utilizou-se como descritores as palavras-chave: docência na EJA, docência e EJA e ensino na EJA.

Como resultados, localizaram-se, nos últimos cinco anos, quatorze Dissertações de Mestrado, apresentadas no quadro que segue.

Quadro 2 - Pesquisas sobre Docência na EJA em Universidades Públicas/RS

\begin{tabular}{|c|c|c|}
\hline Título da Pesquisa & Instituição & Programa \\
\hline $\begin{array}{l}\text { 1- A certificação pelo Exame Nacional } \\
\text { do Ensino Médio: Implicações no }\end{array}$ & $\begin{array}{c}\text { Universidade Federal } \\
\text { de Pelotas/UFPel }\end{array}$ & $\begin{array}{lrr}\text { Programa } & \text { de } & \text { Pós- } \\
\text { Graduação } & & \text { em }\end{array}$ \\
\hline
\end{tabular}

\footnotetext{
${ }^{11}$ Disponível em: https://www.lume.ufrgs.br/. Acesso em 10 de novembro de 2018.
} 


\begin{tabular}{|c|c|c|}
\hline $\begin{array}{l}\text { currículo e no trabalho docente da } \\
\text { educação de jovens e adultos. Simone } \\
\text { Gonçalves da Silva - } 2014\end{array}$ & & Educação \\
\hline $\begin{array}{l}\text { 2- Formação } \\
\text { professores } \quad(\mathbf{a s}) \\
\text { da } \text { EJA: círculo } \\
\text { dialógico como práxis pedagógicas. } \\
\text { Eliziane Taina L. Ribeiro - } 2014\end{array}$ & $\begin{array}{l}\text { Universidade Federal } \\
\text { de Santa Maria/UFSM }\end{array}$ & $\begin{array}{lrr}\text { Programa } & \text { de } & \text { Pós- } \\
\text { Graduação } & \text { em } \\
\text { Educação } & & \end{array}$ \\
\hline $\begin{array}{l}\text { 3- A implementação de um curso de } \\
\text { Ensino Médio Integrado na } \\
\text { modalidade EJA: contexto da prática do } \\
\text { Campus Restinga (IFRS). Guilherme } \\
\text { Brandt de Oliveira - } 2014\end{array}$ & $\begin{array}{l}\text { Universidade Federal } \\
\text { do Rio Grande do } \\
\text { Sul/UFRGS }\end{array}$ & $\begin{array}{lrr}\text { Programa } & \text { de } & \text { Pós- } \\
\text { Graduação } & \text { em } \\
\text { Educação } & & \end{array}$ \\
\hline $\begin{array}{l}\text { 4- Institucionalização escolar } \\
\text { empreendedorismo: } \\
\text { governamentalidade } \quad \text { efeitos } \\
\text { sujeição do aluno da EJA. Elize de Matos } \\
\text { Souto - } 2014\end{array}$ & $\begin{array}{l}\text { Universidade Federal } \\
\text { de Santa Maria/UFSM }\end{array}$ & $\begin{array}{lrr}\text { Programa } & \text { de } & \text { Pós- } \\
\text { Graduação } & \text { em } \\
\text { Educação } & & \end{array}$ \\
\hline $\begin{array}{l}\text { 5-Abordagem Interdisciplinar a partir } \\
\text { da temática energia: contribuições para } \\
\text { uma aprendizagem significativa na EJA. } \\
\text { André Taschetto Gomes - } 2014\end{array}$ & $\begin{array}{l}\text { Universidade Federal } \\
\text { de Santa Maria/UFSM }\end{array}$ & $\begin{array}{lrr}\text { Programa } & \text { de } & \text { Pós- } \\
\text { Graduação } & & \text { em } \\
\text { Educação } & & \end{array}$ \\
\hline $\begin{array}{l}\text { 6- Educação Patrimonial e Educação } \\
\text { de Jovens e Adultos: uma experiência } \\
\text { na Escola Marieta D'Ambrosio em Santa } \\
\text { Maria/RS. Neida Maria C. de Freitas - } \\
2014\end{array}$ & $\begin{array}{l}\text { Universidade Federal } \\
\text { de Santa Maria/UFSM }\end{array}$ & $\begin{array}{lrr}\text { Programa } & \text { de } & \text { Pós- } \\
\text { Graduação } & & \text { em } \\
\text { Educação } & & \end{array}$ \\
\hline
\end{tabular}




\begin{tabular}{|c|c|c|}
\hline $\begin{array}{l}\text { 7- O Estado do Conhecimento Sobre o } \\
\text { Ensino de História na EJA: um estudo } \\
\text { a partir dos anais dos simpósios da } \\
\text { Associação Nacional de História } \\
\text { (ANPUH-BRASIL) 1961-2015. Cláudia } \\
\text { Smuk da Rocha - } 2016\end{array}$ & $\begin{array}{c}\text { Universidade Federal } \\
\text { da Fronteira Sul }\end{array}$ & $\begin{array}{llr}\text { Programa } & \text { de } & \text { Pós- } \\
\text { Graduação } & & \text { em } \\
\text { Educação } & & \end{array}$ \\
\hline $\begin{array}{l}\text { 8- Etnomatemática e Educação de } \\
\text { Jovens e Adultos: diálogos de uma } \\
\text { prática educativa voltada para o social. } \\
\text { Vanessa Silva da Luz - } 2017\end{array}$ & $\begin{array}{l}\text { Universidade Federal } \\
\text { do Rio Grande/FURG }\end{array}$ & $\begin{array}{l}\text { Programa de Pós- } \\
\text { Graduação } \\
\text { Educação e Ciências }\end{array}$ \\
\hline $\begin{array}{l}\text { 9- Alfabetização Espacial na } \\
\text { Aprendizagem de Jovens e Adultos: } \\
\text { um diário de aventuras. } \\
\text { Antonio N. Vicente }-2015\end{array}$ & $\begin{array}{c}\text { Universidade Federal } \\
\text { do Rio Grande do Sul/ } \\
\text { UFRGS }\end{array}$ & $\begin{array}{llr}\text { Programa } & \text { de } & \text { Pós- } \\
\text { Graduação } & & \text { em } \\
\text { Geografia } & & \end{array}$ \\
\hline $\begin{array}{l}\text { 11-Sistematização de } \text { Estudo na } \\
\text { Educação de Jovens e Adultos: } \\
\text { possibilidade a partir da utilização de } \\
\text { roteiros de aprendizagem no ensino de } \\
\text { química. Mauro Melo Costa }-2017\end{array}$ & $\begin{array}{c}\text { Universidade Federal } \\
\text { do Rio Grande do Sul/ } \\
\text { UFRGS }\end{array}$ & $\begin{array}{lr}\text { Programa de } & \text { Pós- } \\
\text { Graduação } & \text { em } \\
\text { Educação em Ciências }\end{array}$ \\
\hline $\begin{array}{l}\text { 12- Geografias da Educação de Jovens } \\
\text { e Adultos: um estudo em escolas } \\
\text { públicas de Canguçu/RS. Adriana Dal } \\
\text { Molin - } 2016\end{array}$ & $\begin{array}{c}\text { Universidade Federal } \\
\text { de Pelotas/UFPel }\end{array}$ & $\begin{array}{ll}\text { Programa de } & \\
\text { Graduação } & \\
\text { Geografia } & \end{array}$ \\
\hline $\begin{array}{l}\text { 13- A prática docente do EJA no } \\
\text { Distrito prisional: um estudo da } \\
\text { psicodinâmica do trabalho. Marcela } \\
\text { Haupt Bessil - } 2015\end{array}$ & $\begin{array}{c}\text { Universidade Federal } \\
\text { do Rio Grande do Sul/ } \\
\text { UFRGS }\end{array}$ & 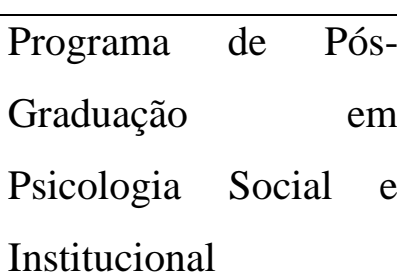 \\
\hline
\end{tabular}




\begin{tabular}{|c|c|c|}
\hline $\begin{array}{l}\text { 14- A Formação Inicial de Professores } \\
\text { das Licenciaturas para Educação de } \\
\text { Jovens e Adultos no Ensino Médio: } \\
\text { desafios e possibilidades. Nisiael de } \\
\text { Oliveira Koufman - } 2015\end{array}$ & $\begin{array}{l}\text { Universidade Federal } \\
\text { de Santa Maria/UFSM }\end{array}$ & $\begin{array}{lll}\text { Programa } & \text { de } & \text { Pós- } \\
\text { Graduação } & & \text { em } \\
\text { Educação } & & \end{array}$ \\
\hline
\end{tabular}

Fonte: http://www.lume.ufrgs.br. Acesso em 20 de junho de 2018 - Quadro elaborado pelas autoras.

Como é possível observar, quatro dissertações analisam as políticas públicas e políticas educacionais, com base na pesquisa sobre oferta pública de vaga, de programa e institucionalização da EJA: (1,3,4 e 12). Seis dissertações consistem em estudos de caso, relatos analíticos ou sistematizações de experiências e práticas nas áreas do conhecimento ou em componentes curriculares como Ciências, Matemática, Geografia, Química e História: (5, 6, 8, 9 e 11). Duas dissertações são sobre o estado do conhecimento, referentes ao ensino da História e da Educação Física em escolas de EJA: (7 e 10). Uma dissertação analisa a prática docente no sistema prisional sob as lentes da psicologia e das especificidades da docência no cárcere: (13).

Apenas duas dissertações têm foco, de forma direta, na docência na EJA e nos processos formativos dos professores para atuarem nessa modalidade, uma na formação inicial e outra na formação continuada: (2 e 14). Esses dados, são ainda parciais, mas significativos para se pensar, pois há poucas dissertações, como produções dos programas de pós-graduação nas IES públicas, nos últimos cinco anos, com foco em docência na EJA.

\section{Formação Inicial: Abordagens de EJA nos Projetos de Cursos de Licenciaturas da Universidade Estadual do Rio Grande do Sul}

Este recorte apresenta um olhar sob as lentes de uma investigação, tendo por base as abordagens de EJA nos projetos de Curso de licenciatura da UERGS. Trata-se de um projeto piloto, que em breve constituirá pesquisa mais abrangente sobre os cursos de licenciaturas da IES públicas do Rio Grande do Sul.

Sabe-se que por força de Lei 9394 (BRASIL, 1996) e das Diretrizes Curriculares (BRASIL, 2000) a EJA propõe-se a ser reparadora (com o compromisso de regularizar uma situação histórica, do ponto de vista da vigência de políticas públicas excludentes); qualificadora,(garantindo-se que os conhecimentos dos jovens e adultos articulem-se aos universalmente construídos, de forma adequada); equalizadora, (pensada e constituída por 
processos pedagógicos que satisfaçam as necessidades de aprendizagens de seus estudantes) e permanente, (ao longo da vida, com base em demandas diversas) constituindo-se como uma modalidade de aprendizagem discente, docente e social; momento e local onde se tecem múltiplas relações sociais e de cidadania.

Então, para gestar este ato de cidadania, conforme afirmam Lucena e Costa (2014, p. 44):

O que precisamos entender é a necessidade de ver a formação em sua complexidade e abrangência, de forma a carregar consigo a marca da concepção de professor, como o profissional que lida com a educação, enquanto prática social em constante transformação e, nesse contexto, com o conhecimento sistematizado, visando a emancipação do homem. Dessa forma, o professor é um intelectual, em processo contínuo de construção.

Há uma "realidade educacional a descobrir" na EJA, que é amplamente afetada por um processo de "inversão epistemológica ${ }^{12}$ " que abrange a construção do currículo pensado para um contexto específico desta modalidade, o que requer do professor uma postura investigativa constante e processo de "escuta" vigilante no que concerne o diálogo a ser estabelecido com os estudantes. Assim, enfatiza-se com esta pesquisa a necessidade da constituição de uma formação inicial em EJA, que possua carga horária em currículo abrangente e significativo frente às especificidades colocadas pela Educação de Jovens e Adultos nas licenciaturas em geral, em especial, na Universidade Estadual do Rio Grande do Sul, instituição que, desde a sua origem, caracteriza-se por ser inclusiva ${ }^{13}$.

Como universidade pública multicampi, contendo 24 (vinte e quatro) unidades universitárias em diferentes regiões do estado, a UERGS foi criada em 2001 e tem por compromisso central a formação humana pautada na promoção do desenvolvimento regional sustentável no Estado. Para tanto, seus cursos devem atender a demandas e necessidades regionais, o que lhes fornece características regionalizadas.

No âmbito da formação docente, oferece, de modo regular, os cursos de Licenciatura em Pedagogia, nas Unidades em Alegrete, Bagé, Cruz Alta, Osório, São Francisco de Paula e São Luís Gonzaga; Artes Visuais, Dança, Música e Teatro; Letras, em Porto Alegre e em Ciências Agrárias, na Unidade em Vacaria. Sobre os Projetos Pedagógicos desses cursos torna-se importante apontar algumas informações.

A metodologia utilizada nessa investigação parte dos pressupostos da pesquisa qualitativa em educação. Salienta-se, assim, que prevalecem na análise geral sobre as

\footnotetext{
${ }^{12}$ Revisitando reflexões obtidas em diálogos entre Dresch e Sant'Anna em longas conversas sobre a formação do educador da EJA e em Dresch (2012).

${ }^{13}$ Conforme o seu Projeto político- Pedagógico Institucional (2012) a UERGS possui reserva de vagas para pessoas carentes, economicamente, com necessidades educativas especiais e também, cotas.
} 
informações coletadas, a qualidade das mesmas, e essas são passíveis das interpretações sobre as realidades apresentadas. Conforme Minayo (2007), a pesquisa qualitativa deve ter como principal preocupação, a lógica que permeia a prática que se dá na realidade, correspondendo a um processo mais profundo de relações, processos e fenômenos que não podem ser reduzidos, a variáveis, a priori, já que a pesquisa qualitativa se constitui na co-participação entre os sujeitos envolvidos no processo, que corroboram os sentidos, significados e representações sociais, que permeiam os espaços investigados. Nessa perspectiva, a metodologia, juntamente com análise dos dados, constituir-se-á na especificação e explicitação de um corpus teórico que permita a constituição de um campo de conhecimento capaz de reler e ressignificar a própria EJA.

Do ponto de vista metodológico, a etapa exploratória abrangida nesse recorte envolve análise dos projetos pedagógicos de cursos verificando se há ocorrência ou não, de abordagens de aspectos da Educação de Jovens e Adultos nos currículos dos cursos de licenciatura ofertados pela Uergs. Para tanto, foram verificados aspectos gerais das propostas, mas especialmente visando localizar as disciplinas que abrangem a EJA, suas ementas, objetivos, programas e bibliografia, tendo como descritores a serem localizados, os seguintes termos: Educação de Jovens e Adultos, EJA e Educação de pessoas jovens e adultas.

Como resultados verifica-se, nas análises até o presente momento, que o Curso de Pedagogia - Licenciatura é o que apresenta componentes curriculares significativos para uma formação inicial no âmbito da $\mathrm{EJA}^{14}$. De um modo geral, são 495 horas em disciplinas Obrigatórias e 90 horas em disciplinas eletivas, sendo que, pelo menos uma disciplina eletiva deve ser feita pelo licenciando, efetivando-se, no mínimo, o cumprimento de 525 horas de componentes curriculares, sendo incluídos os de EJA. Bem como aponta Rocha (2018) evidencia-se que dentre as 11 disciplinas que abordam a EJA, 5 disciplinas fornecem um referencial teórico consistente para a modalidade, por abrangerem conceitos, concepções, referenciais e reflexões que, conforme suas ementas, aliam teoria à prática. Essas abordam elementos que dialogam com uma concepção crítica de EJA, pautadas em referencias teóricos que envolvem os aspectos políticos, históricos, filosóficos e ideológicos acerca da modalidade.

\footnotetext{
${ }^{14}$ Psicologia e educação (4 créditos), Educação de Jovens e adultos (4 créditos),Práticas corporais: EJA (2 créditos), Alfabetização: EJA (4 créditos), Educação em ciências naturais: EJA (2 créditos), Educação em ciências sociais (2 créditos), Educação matemática EJA (2 créditos), Estágio III Educação de Jovens e Adultos em espaços escolares e não escolares ( 9 créditos), Planejamento, gestão e avaliação de processos educativos não escolares (4 créditos), como obrigatórias. As optativas são: Concepções e métodos da Educação Popular (2 créditos), Educação, vida adulta e terceira idade ( 2 créditos) e Andragogia: aprendizagem de adultos ( 2 créditos).
} 
Chama a atenção para a concentração de disciplinas no sétimo semestre e a presença do componente curricular "Educação de Jovens e Adultos, apenas no $6^{\circ}$ semestre". Destaca-se a presença de estágio curricular obrigatório de EJA. Outro fator interessante na perspectiva de Rocha (2018), consiste na presença da Andragogia como elemento fundante da aprendizagem de adultos. Chama a atenção de que em nenhum dos cursos analisados, identificou-se reflexão sobre essa concepção teórico-metodológica para a EJA.

Nos PPCS dos cursos de Licenciatura em Teatro e Dança não há ocorrências dos termos da pesquisa, mas localiza-se um ou mais componentes curriculares, presentes nos PPCs dos quatro cursos (Dança, Teatro, Artes Visuais e Música), envolvendo temáticas de "Educação e pluralidade cultural", abrangendo "cultura popular, educação popular e educação diferenciada" apresentando alguns poucos referenciais, que podem aproximar-se da EJA, o que será melhor investigado em etapa futura da pesquisa. Registra-se que no PPC de Música há a presença da expressão "Educação de Jovens e Adultos, na introdução e em uma referência legal, que anuncia as Diretrizes Curriculares da Educação de Jovens e Adultos, mas sem ocorrências no ementário dos componentes.

No PPC de Artes Visuais é importante salientar a presença de quatro componentes curriculares que fazem abordagem ao termo "EJA" e nos PPCs de Letras e de Licenciatura em Ciências Agrárias aparecem apenas uma disciplina eletiva com abordagem sobre a "Educação de Jovens e Adultos" e a "EJA", o que não garante a matrícula dos estudantes, já que há outras disciplinas em oferta para escolha. No decorrer da pesquisa buscar-se-á informações mais detalhadas sobre os planos de ensino destes componentes. O termo educação de pessoas jovens e adultas não aparece em nenhum PPC e bibliografias com abordagens de EJA, são, praticamente inexistentes.

Embora ainda sejam análises parciais, o que fica deste estudo é a necessidade de se ampliar as reflexões e o diálogo interno, tendo por foco o reconhecimento da EJA nos demais currículos de licenciatura. Assim, a Universidade terá que centrar esforços para atender ao Artigo $1^{\circ}$ da Resolução n 343 do Conselho Estadual de Educação (RIO GRANDE DO SUL, 2018), que postula, em seu parágrafo sétimo: “As instituições de ensino superior do Sistema Estadual de Ensino devem garantir nos currículos de formação inicial, em suas diferentes licenciaturas e nas propostas de formação continuada para profissionais de educação, as demandas desse campo especializado em que se constitui a EJA". Dessa forma, faz-se necessário, com urgência, que se desfaçam as ausências e silenciamentos que ecoam em boa parte dos PPCs dos cursos de licenciaturas da Universidade, no que tange à Educação de Jovens e Adultos na formação inicial. 


\section{Sobre oferta de EJA/Educação Básica, Núcleos e Grupos de Pesquisa}

A EJA tem sido relegada a políticas restritivas no Rio Grande do Sul, o que gerou a redução de sua oferta nos estabelecimentos de ensino, conforme revelam estudos de Alves, Comerlato e Sant'Anna (2017), assim como a diminuição do quadro docente da EJA nas escolas, o que vem "colocando em cheque" e distanciando o cumprimento de algumas metas propostas no Plano Nacional de Educação $(2014-2024)^{15}$, como bem enunciam Machado e Alves (2017), em seus estudos. No sentido de "dar visibilidade sobre a configuração da EJA no Estado, esse estudo realizou um "mapeamento quantitativo da oferta de vagas para a EJA nas redes de ensino (Municipal, Estadual, Federal e Particular) no Rio Grande do Sul" além da produção de um cálculo, regionalizado, da demanda potencial de EJA no Estado. A metodologia envolveu um estudo quantitativo de acompanhamento longitudinal da oferta de vagas para a EJA nas redes municipal, estadual federal e particular, conforme quadro que segue:

Ilustração 1 - Oferta de vagas para a EJA no estado do Rio Grande do Sul

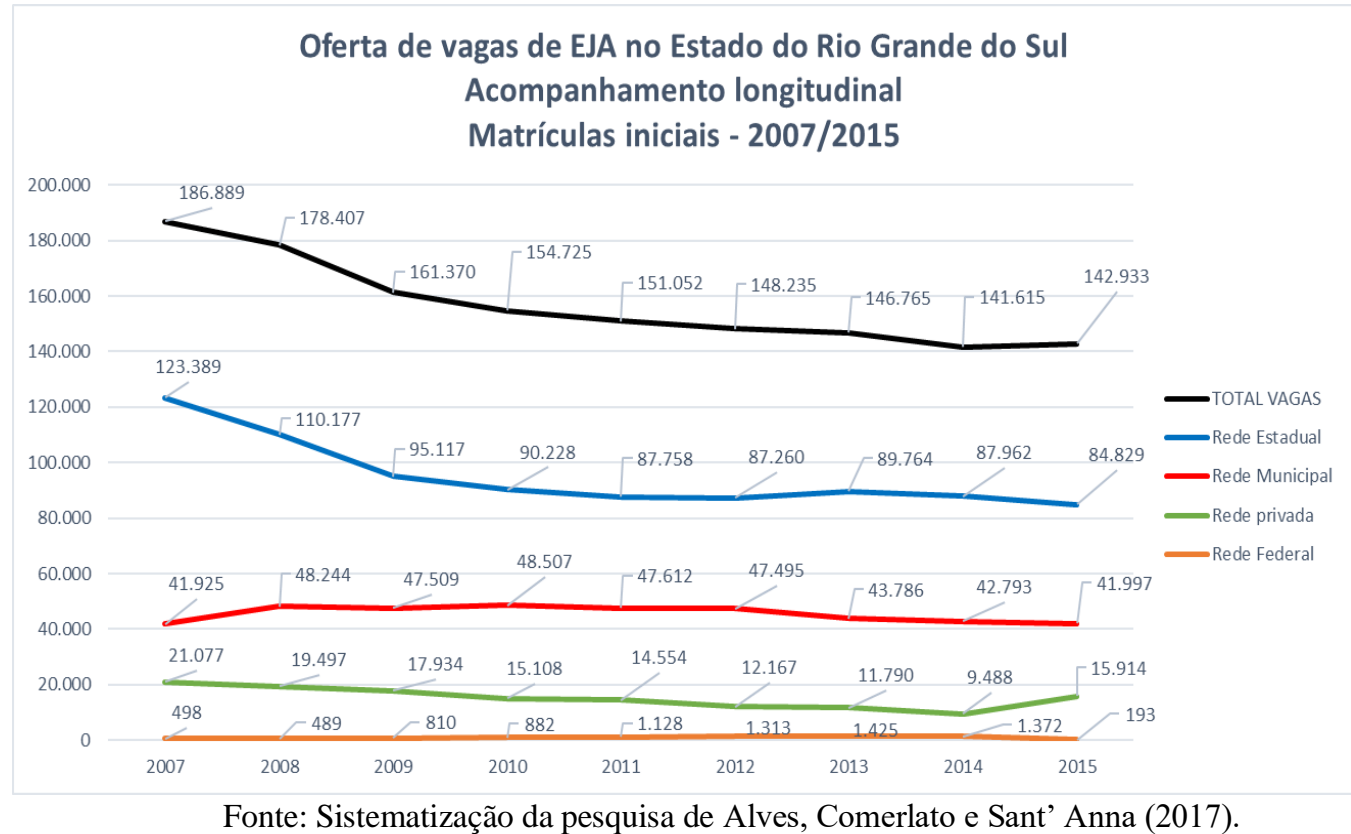

15 O Plano Nacional de Educação, em sua competência de 2014 a 2024 contempla a EJA, de forma direta, nas metas 3, 8, 9, 10 e 11. Meta 8: elevar a escolaridade média da população de 18 (dezoito) a 29 (vinte e nove) anos, de modo a alcançar, no mínimo, 12 (doze) anos de estudo no último ano de vigência deste plano, para as populações do campo, da região de menor escolaridade no País e dos $25 \%$ (vinte e cinco por cento) mais pobres, e igualar a escolaridade média entre negros e não negros declarados à Fundação Instituto Brasileiro de Geografia e Estatística - IBGE; Meta 9: elevar a taxa de alfabetização da população com 15 (quinze) anos ou mais para 93,5\% (noventa e três inteiros e cinco décimos por cento) até 2015 e, até o final da vigência deste PNE, erradicar o analfabetismo absoluto e reduzir em $50 \%$ (cinquenta por cento) a taxa de analfabetismo funcional; Meta 10: oferecer, no mínimo, $25 \%$ (vinte e cinco por cento) das matrículas de educação de jovens e adultos, nos ensinos fundamental e médio, na forma integrada à educação profissional; Meta 11: Triplicar as matrículas da educação profissional técnica de nível médio. 
Cabe frisar, que conforme esse estudo ${ }^{16}$, a queda expressiva na oferta de vagas, por parte da rede estadual é visível. Ao mesmo tempo, é essa a rede que mais oferta vagas no período. A rede municipal "mantêm certa estabilidade na oferta de vagas" e o aumento significativo da oferta ocorre por conta da rede privada. Os pesquisadores apontam um "leve acréscimo" na oferta da rede federal, "seguramente por englobar a ampliação do Programa Nacional de Integração Profissional com a Educação Básica na modalidade de Educação de Jovens e Adultos - PROEJA".

Outra pesquisa localizada, está em andamento e é coordenada por Santos (2018), sob o título "Contextos e resultados da elevação da escolaridade e da profissionalização: um estudo das experiências pedagógicas junto a egressos da EJA e do PROEJA das instituições federais de educação no RS" com a finalidade mapear as condições dessa oferta. Por estar em etapa inicial de estudo, não estão disponibilizados dados de resultados do estudo.

Conforme informações disponíveis pela gestão dos Institutos Federais de Educação, Ciência e Tecnologia no Rio Grande do Sul, há uma oferta de 700 matrículas no campo da EJA, em 2018. Com base no projeto de pesquisa coordenado por Santos (2018) obtém-se informações que o Colégio de Aplicação da Universidade Federal do Rio Grande do Sul oferece 130 vagas para matrícula na Educação Básica de EJA, envolvendo os anos iniciais e finais do Ensino Fundamental e Ensino Médio.

Quanto aos Grupos de Pesquisa, no Diretório de Grupo de Pesquisa - DGP do CNPq, com termo de busca (em todas as palavras): Educação de Jovens e Adultos; EJA e Educação de pessoas jovens e adultas, na situação "certificado" - Região Sul- RS e aplicação de busca, com base em nome de grupo e nome da linha de pesquisa, localiza-se o registro de dois grupos, que são: Educação de Jovens e Adultos em espaços escolares e não- escolares, da Universidade Federal do Rio Grande do Sul e Educação de Jovens e Adultos: docência, formação de professores e processos pedagógicos da EJA, da Universidade Estadual do Rio Grande do $\mathrm{Sul}^{17}$.

No que tange à presença de núcleos de qualquer natureza, localiza-se, entre as 9 IES públicas, apenas um "Núcleo Interdisciplinar de Ensino, Pesquisa e Extensão em Educação de Jovens e Adultos"18, em funcionamento na Faculdade de Educação da UFRGS.

\footnotetext{
${ }^{16}$ Localizado, na íntegra, em http://www.ufrgs.br/niepeeja. Acessado em dezembro de 2018.

17 Atualizada em 13/12/2018.

${ }^{18}$ Site: http://www.ufrgs.br/niepeeja Acessado em mar. 2019.
} 


\section{Considerações Finais}

O presente artigo não tem o objetivo de apontar afirmações conclusivas, mas de evidenciar um panorama do que se desenha nas IES públicas do Rio Grande do Sul em relação à docência na EJA, no período, no âmbito da pesquisa, abrangendo, também, a oferta da formação docente para essa modalidade de ensino, por parte das instituições investigadas. Além disso, no âmbito da oferta pública, chama a atenção para a redução de vagas, por contas das políticas restritivas de estado, na Educação Básica.

Pensar a docência em EJA pressupõe constituir-se do geral e também, das especificidades que a modalidade exige. A partir dos estudos sobre docência apresentados, pode-se afirmar que a mesma se mostra multirreferenciada, por diferentes nuances. Enquanto campo de saber e de conhecer, requer formação específica, reflexão e aprofundamentos constantes. No âmbito do levantamento das pesquisas strictu sensu que tratam da docência foi possível perceber que a maioria dos trabalhos não aprofundaram em que constituem tal docência. Nesse contexto, localizou-se somente duas dissertações, no período, tendo como objeto à docência na EJA.

Este cenário aponta que a Educação de Jovens a Adultos se apresenta como um campo árido de estudos, no âmbito dos cursos de Pós-Graduação nas IES do Rio Grande do Sul. De alguma forma, a pequena presença de núcleos ou Grupos de Ensino, Pesquisa e Extensão em Educação de Jovens e Adultos reflete um convite à mudança.

Importante salientar, que embora reafirmemos a necessidade de adequação dos PPCs dos cursos de licenciatura nas IES públicas, estes estudos apresentados neste $\operatorname{artigo}^{19}$, em geral, já surtem um certo efeito, tanto no que tange à ampliação de núcleos e grupos de pesquisa nas IES públicas, quanto no que se refere a movimentos de revisão dos currículos das licenciaturas. Este, talvez, seja o mais significativo entre os impactos já observados, empiricamente e carecerá de uma retomada e atualização nos dados e informações apontadas nestes estudos, no futuro.

\footnotetext{
${ }^{19}$ Alguns excertos deste texto foram apresentados em painel, no V Encontro Internacional de Alfabetização e Educação de Jovens e Adultos - ALFAeEJA, realizado em Porto alegre, de 12 a 14 de novembro de 2018 e em Jaguarão, nos eventos conjuntos: VI Semana do curso de Pedagogia, I Encontro dos cursos de Pedagogia presencial e licenciaturas à distância da Unipampa, I Mostra científica da Pós-Graduação do Campus Jaguarão e II Fórum Regional de EJA da metade SUL e XXII Encontro Estadual do Fórum EJA RS, intitulado: Juntos por uma universidade pública, inclusiva, gratuita e de qualidade.
} 


\section{Referências}

BRASIL. Lei de Diretrizes e Bases da Educação Nacional. Lei 9394/96. Brasília, 1996. . Constituição (1988). Constituição da República Federativa do Brasil. Brasília, DF:

Senado, 1998.

ALVES, Evandro; COMERLATO, Denise Maria; SANT'ANNA, Sita Mara Lopes. Mapa da EJA no RS: Estudos sobre demanda potencial pela Educação de Jovens e Adultos em Porto Alegre: Subsídios para a luta pelo não desmantelamento da EJA municipal. UFRGS, 2017. Disponível em: http://www.ufrgs.br/niepeeja/mapa-da-educacao-de-jovens-e-adultos-no-rs . Acesso em: 10 nov. 2018.

2000 .

Diretrizes Curriculares Nacionais para a Educação de Jovens e Adultos. Brasília, Brasil.

Instituto de Pesquisa Econômica Aplicada. Atlas do Desenvolvimento Humano no

DRESCH, N. Ações de ATER como EJA: impactos e Indicadores Territoriais de avaliação para a sustentabilidade de famílias de agricultores e formação extensionista. Tese

(Doutorado). Programa de Pós-Graduação em Desenvolvimento Rural. Universidade Federal do Rio Grande do Sul, Porto Alegre, 2012.

GIL, A.C. Métodos e técnicas da pesquisa social. São Paulo: Atlas, 2008.

LAFFIN, M.H.F. A constituição da docência entre professores de escolarização inicial de jovens e adultos. Herói: Unijuí, 2013.

LUCENA, M. S. COSTA, E. A formação do professor para o trabalho em Educação de Jovens e Adultos. In: Estágios supervisionados na firmação docente: educação básica e Educação de Jovens e adultos. São Paulo: Cortez, 2014.

MACHADO, Maria Margarida.; ALVES, Mirian. O PNE e os desafios da Educação de Jovens e adultos na próxima década. In: http://forumeja.org.br/go/sites/

forumeja.org.br.go/files/texto1margaridamirian.pdf . 2017. Acesso em 9 novembro de 2018.

MINAYO, M. C. S. (org.) DESLANDES, S.F., NETO, O.C., GOMES, C. Pesquisa Social: teoria, método e criatividade. Petrópolis: Vozes, 1994, $21^{\text {a }}$ edição.

NÓVOA, A. Os professores e a sua formação. Lisboa: Dom Quixote, 1992. ISBN 972-201008-5. pp. 13-33.

ORLANDI, E.P. A Linguagem e seu funcionamento: as formas do discurso. São Paulo: Brasiliense, 1993.

. Análise do Discurso: princípios e procedimentos. Campinas: Pontes, 1999.

PÊCHEUX, M. O discurso: estrutura ou acontecimento. Tradução de Eni Pulcinelli Orlandi.

Campinas: Pontes, 1990. 
PERRENOUD, P. Dez Novas Competências para Ensinar. Porto Alegre: Artmed, 2000.

ROCHA, E. Formação inicial de professores da Educação de Jovens e Adultos no Rio Grande do Sul. Programa de Pós-Graduação em Educação. Universidade Federal de Santa Catarina. Dissertação de Mestrado. Florianópolis, 2018.

SANT'ANNA, S. M. L. Ensino Supletivo ou EJA? Sentidos e perspectivas da formação continuada de professores do Rio Grande do Sul. Revista Educação, Ciência e Cultura (ISSN 2236-6377), Canoas, n. 2, 2015.

Os sentidos nas perguntas dos professores da Educação de Jovens e Adultos. 2009. 200 f. Tese (Doutorado em Educação) - Universidade Federal do Rio Grande do Sul, Porto Alegre, 2009.

SOARES, L. J. G. O educador de jovens e adultos; um estudo sobre a habilitação de EJA dos cursos de pedagogia do país. IN: XIV ENDIPE - Encontro Nacional de Didática e Prática de Ensino. Porto Alegre, 2008. CD.

SPIES, J.; FISS, D. M. L. Identidades Docentes, Charges e Crise do/no Magistério, Efeitos de Sentido. Revista Reflexão e Ação, Santa Cruz do Sul, v. 23, n. 1, p. 100-130, jan./jun. 2015.

TARDIF, M. Saberes docentes e formação profissional. Petrópolis: Vozes, 2002 